\title{
Contextualizing ICT in Africa: The Development of the CATI Model in Tanzanian Higher Education
}

\author{
Vesisenaho, Mikko; Kemppainen, Jyri; Islas Sedano, Carolina; \\ Tedre, Matti \& Sutinen, Erkki \\ University of Joensuu, Finland \\ \{mvaho, jkemppai, cislas, mmeri, sutinen\}@cs.joensuu.fi \\ P.O.Box 111, 80101 Joensuu \\ tel. +35813251 7929, fax. +358132517955
}

\begin{abstract}
In many parts of Africa the application of information and communication technologies (ICTs) in higher education institutions offers a particularly interesting research problem. This is because of the far-reaching consequences that information and communication technology (ICT) services and education have on the university graduates during their careers in African societies. Our extensive and well-documented experience of utilizing ICTs in a Tanzanian private university has lead us to propose a four-level approach, called CATI model, that can be used as the basis for implementing new ICTs, for evaluating how ICT is used, and for planning ICT education in developing countries. We conceptually categorize the four levels that we use in our model - contextualize, apply, transfer and import - as an ethnocomputing approach. This four-level model enable educators to use ICT services and ICT education in African universities in a way that will prepare university graduates to make a positive contribution to their own societies. The success of this model is attributable to the emphasis that we placed on local needs and creativity and on applications of ICTs that were sensitive to local culture, conditions and understanding.
\end{abstract}

Keywords: contextualized teaching, ethnocomputing, ICT education in developing countries

\section{Introduction}

The vision of the World Summit on the Information Society (WSIS) [1] is that all people throughout the world be given the opportunity to use information and communication technologies (ICTs). The vision specifically makes a plea for schools and other educational institutions whether rural, urban, rich, or poor - not to be excluded from the benefits of ICTs. The WSIS vision thus addresses an issue that is both topical and important: inequality in the use of new technologies. While the pervasive effects of globalization and the sharing of ideas and new technologies constantly create new needs and opportunities in highly developed societies, the benefits of such opportunities are seldom disseminated in developing countries. One of these needs (one that is especially topical in Africa at present) is the need to integrate new ICTs with educational philosophies in such a way that the synthesis thus created harmonizes with local cultures and environments.

The WSIS action plan [2] also encourages the development of content and technical conditions that facilitate the presence and use of all world languages on the Internet. While the advantages of such a development are fairly obvious, there are real problems that have to be identified and addressed before we can ever hope to see ICTs making a truly beneficial impact of local conditions in developing countries. The advantages that ICTs confer in developed societies are fairly obvious. They enable an easier dissemination of knowledge, increased and varied social interaction, more efficient economic and business practices, political empowerment, better access to independent and diverse media, better education, a heightened awareness of health issues, improved health services, and diversified leisure and entertainment possibilities. The main focus of our work has been on developing ways for information technologies and ICT education to support local development without any sacrifice of local identity - especially in higher education institutions.

We have therefore moved away from a merely linear process of importing technology and education from industrialized to developing countries and seek instead to create a novel synthesis between technology, education, and culture that represents a balance between an alien but global technology and local needs. This kind of synthesis, we have found, fertilizes the inherent creativity that is always present in local communities. It also creates a learning community 
that utilises global technology while remaining uniquely local in style, method and content. Local creative learning communities are not restricted to classrooms. They contribute directly to the everyday lives of the learners and local society. By applying ICTs to everyday tasks and concerns, our students retain strong links with local society. They learn to apply their knowledge in the service of others in their immediate environment rather than become self-obsessed consumers of technological novelty in the constantly changing conditions of global information culture.

We undertook this research partly in response to reports on the extent to which Millennium development goals [3] had been achieved. These reports showed that Sub-Saharan Africa still lagged behind other regions in the world and that recent developments in this region had failed to meet the expectations of the WSIS [4]. The expansion of ICT that has lent wings to accelerating economic, environmental, and social development in Western countries has not had the same effect in African countries. Since a key WSIS principle is an "information society for all", one might expect the introduction of ICTs would foster an equal rate of development in all societies. But this has not happened in most countries of Sub-Saharan Africa. What this suggested to us was that it is naïve and simplistic merely to take a foreign technology developed in alien circumstances, introduce it into a local culture and then expect the same benefits to accrue to that culture - which is different in many important ways from the culture in which the technology was originally developed.

While globalization has in some ways contracted the world culturally, it has not eradicated cultural differences between or within countries. One of the effects of globalization is often a kind of international cultural homogenization in which predominantly Western cultural elements and artifacts supersede local elements in non-Western cultures [5]. While cultures are never static, they change (ideally) along different lines and at a different pace. Our preference in these circumstances is for cultural hybridization [5] rather than homogenization. Cultural hybridization promotes the retention of the elements of local cultures and the expectation that it is possible to blend local culture with globalised cultural elements so as to produce a hybridized local style that is unique to its country of origin. There is no inherent reason why technological change should subvert local identities. Our experience has proved that it is possible to use new forms of technology to enrich rather than diminish local knowledge and culture. using a knowledge of local realities, concerns and conditions to build ICT infrastructure and to develop ICT in education. Contextualized ICT should relate ICT infrastructure and education to local needs and everyday life.

Our research projects aim at non-zero-sum development. The benefit to us is that we extend our practical and theoretical knowledge and test technologies in an environment that differs enormously from our own sociocultural environment. The benefit to our partners is that they gain technological know-how and theoretical understanding from ICT education and from using technological tools. And all those involved benefit from the realities of international, interdisciplinary network. We selected Tanzania as our main target area because it became apparent to us that it had not benefited from ICTs to the same extent that many other countries had, and because ICT development had occurred only sporadically in Tanzania which, according to UN reports, is one of the least developed countries (LDCs) in the region [7].

It soon became apparent to us that it was not going to be easy to implement a developmental theory in practice - however well designed and carefully constructed it may have been. It is not a straightforward procedure to introduce and integrate globally functioning but foreign concepts and infrastructure into a society in a manner that is harmonious and that takes respectful cognizance of that local culture. From our perspective, we needed to leave enough room for local initiatives and activities so that they could coevolve in harmony with foreign concepts. Our department runs a number of interconnected research projects, each of which employs a different set of methodologies. Most of our research approaches - such as participatory action research, problem-oriented research, and longitudinal development research - are based on techniques that belong to the ethnographic tradition. This article describes the origins, progress and outcomes of a number of our research projects. Our analysis of these projects and their practical and theoretical implications and concerns contribute to an approach that can be used in the planning, implementation and analysis of ICTs in higher education in developing countries. Since the focus of our research is somewhat narrow, we recognize that our particular approach may not be applicable to all situations at all times. We nevertheless maintain that it remains pertinent to a large number of cases of the kind we are dealing with much of the time. 


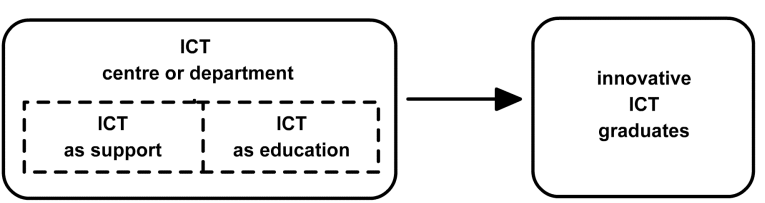

Figure 1: The Dual Role of ICT in a Higher Education Institution.

ICT in higher education institutions serves two functions (see Figure 1). In the first instance, ICT is needed as part of the support infrastructure that maintains an institution as a functioning entity. ICT is necessary in a modern tertiary institution for carrying out teaching and research. Secondly, ICT should ideally be taught as part of a distinctive discipline in its own right to both students and staff. Both these functions are necessary for the education of graduates who will apply ICT in their future professions. Some smaller colleges or universities in Africa tend to have a dedicated ICT centre or department that organizes all ICT services and training rather than one centre for support and another for academic activities (Figure 1). This kind of arrangement is also applied in Western countries where many universities begin with a computer centre before differentiating it into a support centre and a department of computer science at an opportune moment.

It is also generally accepted nowadays that graduates who have not specialized in ICT studies should nevertheless be sufficiently well trained in to use ICTs in their own fields in a competent manner. Students who graduate with a mastery of ICT will be in a far stronger position to advance their careers than students whose computer literacy is limited to a few standard applications.

The fact of the two roles or functions of ICT in higher education institutions is also evident in the WSIS key principles for an information society for all [1]. Table 1 shows that each WSIS principle needs to be addressed either by ICT support or by ICT education. Consider, for example, capacity building. Functional ICT support, such as an efficient library system, is a prerequisite for capacity building. Another important point is that all the WSIS principles are context sensitive. By this we mean that the cultural context of the user community needs to be taken into account when a principle is applied. Thus, for example, successful access to information and knowledge depends on the skills, attitudes, and values of the people who are in the need of information. It follows from this that both ICT support services and ICT teaching in higher education institutions need to be contextualized.

The implementation of key WSIS principles depends on long-term strategies. This makes them amenable to short-term planning (such as that which is based on three-month periods). Strategies are difficult to describe in rigid detail because their success and failure depend on long-term changes and variations such as those

Table 1: The Key WSIS principles

\begin{tabular}{|l|c|c|c|}
\hline \multicolumn{1}{|c|}{ Key WSIS principles } & $\begin{array}{c}\text { ICT } \\
\text { support }\end{array}$ & $\begin{array}{c}\text { ICT } \\
\text { education }\end{array}$ & $\begin{array}{c}\text { Context } \\
\text { sensitive }\end{array}$ \\
\hline $\begin{array}{l}\text { 1. The role of governments and all stakeholders in the } \\
\text { promotion of ICTs for development }\end{array}$ & $\sqrt{ }$ & $\sqrt{ }$ & $\sqrt{ }$ \\
\hline 2. Information and communication infrastructure & $\sqrt{ }$ & $\sqrt{ }$ & $\sqrt{ }$ \\
\hline 3. Access to information and knowledge & $\sqrt{ }$ & $\sqrt{ }$ & $\sqrt{ }$ \\
\hline 4. Capacity building & $\sqrt{ }$ & $\sqrt{ }$ \\
\hline 5. Building confidence and security in the use of ICTs & & $\sqrt{ }$ & $\sqrt{ }$ \\
\hline 6. Enabling environment & & $\sqrt{ }$ & $\sqrt{ }$ \\
\hline 7. ICT applications: benefits in all aspects of life & & $\sqrt{ }$ \\
\hline 8. Cultural diversity and identity, linguistic diversity and & & $\sqrt{ }$ & $\sqrt{ }$ \\
\hline local content & & $\sqrt{ }$ & $\sqrt{ }$ \\
\hline 9. Media & $\sqrt{ }$ & $\sqrt{ }$ & \\
\hline 10. Ethical dimensions of the Information Society & & & $\sqrt{ }$ \\
\hline 11. International and regional cooperation & & & $\sqrt{ }$ \\
\hline
\end{tabular}


Table 2: Educational Institutions that offer ICT Degree Programs in Tanzania (May 2005) [13]

\begin{tabular}{|l|l|l|}
\hline Higher Education Institution & Degree & $\begin{array}{l}\text { Student Enrolment } \\
\text { / Academic year }\end{array}$ \\
\hline Institute of Accountancy, Arusha & Advanced Diploma in Computer Science & 41 / 2004-05 \\
\hline $\begin{array}{l}\text { Institute of Finance Management, } \\
\text { Dar es Salaam }\end{array}$ & $\begin{array}{l}\text { Advanced Diploma in Information } \\
\text { Technology }\end{array}$ & 378 / 2004-05 \\
\hline $\begin{array}{l}\text { Mzumbe University, } \\
\text { Morogoro }\end{array}$ & $\begin{array}{l}\text { B.Sc. in Information, Communications and } \\
\text { Technology Management }\end{array}$ & 33 / 2003-04 \\
\hline University of Dar es Salaam & B.Sc. and M.Sc. in Computer Science & $400 / 2004-05$ \\
\hline
\end{tabular}

that occur in local "grass-roots" socio-economic and political changes, national plans and campaigns, and fluctuations in the global economy. The strategies that we implement in our projects are essentially local-level strategies that arise out of the needs of a university. Their implementation is correspondingly dependent on local circumstances such as the availability of resources (e.g. personnel, electricity, building material) and sociocultural factors (e.g. styles of teaching, learning, administration, decision making).

In the following sections we describe our work in more detail. Section two contains an overview of the role of ICT in Tanzanian education and especially in the Tanzanian higher education system. Section three describes the case study of Tumaini University, Iringa University College. Section four analyses the work detailed in section three within the framework of the CATI model. Section five explains how this project serves as an excellent example of what we have called ethnocomputing [8].

\section{The role of ICT in Tanzanian Higher Education System}

As Mkude et al. [9] state according to the Progress and Financial Reports of University of Dar es Salaam, Africa has been afflicted with every kind of social, political and economic woe over the past two decades and many countries are even now staggering under the burden of domestic and international conflicts, disease (especially HIVIAIDS), poverty, corruption and the effects of natural disasters such as drought. Since the 21 st century is a ime of increasingly globalization, African universities that hope to perpetuate some kind of international reputation will have to be managed by strict discipline and new and more stringent strategies for implementing change. Many African universities, especially those in what the United Nations designates as "least developed countries" (LDCs), will have to further improve the capabilities of their graduates if the universities are to continue to maintain even their current share of the local and international labor market.

Strategic planning in Tanzania is currently guided by a document known as Development Vision 2025 [10]. This document is, in effect, a blueprint for Tanzanian progress. It details what planners think is feasible for the future of Tanzania in terms of education and all the other amenities of a modern and progressive country. Development Vision 2025 stipulates that information and communication technologies represented a primary means for realizing the terms of the vision. Development Vision 2025 shows how much importance Tanzania's rulers attach to the part that ICTs will play in the development process in Tanzania. Tanzania has also its own specific ICT policy [11]. This document describes the key areas in which development in ICT is expected to take place.

Tanzania has no well-established ICT professional profiles - even in terms of its own ICT policy [11]. Neither are there any standardized procedures for evaluating or certifying ICT courses. Access to online and distance learning is limited. Opportunities for training are confined mostly to a few urban centers, and the country's official Secondary School Computer Studies Syllabus is outdated. While private urban schools offer the best opportunities for ICT education, there is no program for training ICT teachers. Universities and other higher education institutions lack computers and ICT amenities. Even in those cases where they do have computers, connectivity is severely limited. Internet access bandwidth for all these institutions was less than $512 \mathrm{kbps}$ for the whole institution in 2003.

Bakari et al. [12] studied ICT in higher education in Tanzania from the security management point of view. While their study indicates that higher education institutions in Tanzania are currently developing ICT strategies, our observation is that 
Table 3: Frequency of Computer Ownership and Number of Internet Users in Tanzania (1999, 2002 and 2003) [14]

\begin{tabular}{|l|r|r|r|}
\hline \multicolumn{1}{|c|}{ Indicator } & $\mathbf{1 9 9 9}$ & $\mathbf{2 0 0 2}$ & $\mathbf{2 0 0 3}$ \\
\hline Population, total (millions) & 32.9 & 35.2 & 35.9 \\
\hline Personal computers (per 1,000 people) & 2.5 & 4.2 & 5.7 \\
\hline Internet users (per 1,000 people) & 0.8 & 2.3 & 7.1 \\
\hline
\end{tabular}

most ICT strategies lack security management. In cases where ICT strategies make provision for security management on paper, such measures are not enforced in practice. This lack of security management in institutions and in national policy planning implies that ICTs are not currently serving the best administrative, research, and educational interests of the country.

There are four higher level education institutions that offer ICT degrees in Tanzania. These are (1) Institute of Accountancy in Arusha, (2) Institute of Finance Management, (3) Mzumbe University and, (4) University of Dar es Salaam (Table 2). [13]

Computer illiteracy is widespread in Tanzania and access to ICT facilities is on the whole extremely limited. The World Bank Group's [14] data profile for Tanzania lists the number of computers and Internet connections in Tanzania (Table 3). Nearly all of these are concentrated in urban areas. The latest available figures (from 2003) show an increase in the number of computers and Internet connections in Tanzania.

\section{ICT at Tumaini University, Iringa University College}

Tumaini University was founded in 1996 by the Evangelical Lutheran Church of Tanzania (ELCT) as a major contribution to higher education in the country. Tumaini University consists of four colleges: Iringa University College (IUCO), Kilimanjaro Christian Medical College (KCMC), Makumira University College (MUCO), and Waldorf College in Dar es Salaam. IUCO, the largest college at Tumaini University, is situated on the northern side of the town of Iringa, the capital of the Iringa region. While the total population of the region is approximately 1,5 million, Iringa municipality has a population of 350,000.[15] In 2004, the college consisted of four faculties: Arts and Social Sciences (including the Department of Journalism and the Department of Education), Business and Economics, Law, and Theology.
The case study described in this section took place between 2000 and 2004 at IUCO. The documented data includes the email databases of one of the authors, Jyri Kemppainen, and a number of official documents from Iringa University.

The student body of the college increased by about $30 \%$ annually in the years between 2000 and 2004, with 670 students enrolling in the academic year 2004-2005. Students come from every region of Tanzania as well as from other African countries such as Botswana, Burundi, Kenya and Malawi. The percentage of female students is approximately $40 \%$. This is significantly higher than the $27 \%$ female average in government universities in Tanzania in 2004 [16].

As a private university, Tumaini University received neither funding nor infrastructure from the Tanzanian government in 1999-2004. Since its inception, IUCO's main donor has been the Evangelical Lutheran Church in America (ELCA). Another major cooperative partner for IUCO has been the Finnish Evangelical Lutheran Mission (FELM). ELCA and FELM have supported IUCO in a number of direct and indirect ways. They have financed construction activities, funded the recruitment of contract teachers for teaching at Tumaini, paid the salaries of administrative staff and volunteers for service in the college, initiated and financed scholarship programs, and arranged for the donation of educational materials such as books and second-hand computers. FELM has included some of IUCO's projects in the Program for Development Cooperation of Nongovernmental Organizations, which is funded by Finnish Government. IUCO's plan to develop ICT teaching and ICT facilities for teaching constitutes an important part of the projects funded by the Finnish government. 
Two former business students from IUCO completed their M.Sc. degrees in computer science at the University of Joensuu in 2002. One of them was subsequently appointed as head of the ICT Department of IUCO in 2003. In 2004 IUCO appointed a Tanzanian ICT expert who had recently completed his B.Sc. studies in computer engineering at the Espoo-Vantaa Institute of Technology, Finland. [17]

Figure 2 shows what will follow in this section. We shall begin by introducing the ICT strategies at IUCO and then proceed to describe the implementation of these strategies. Description of the implementation will be divided into: (1) ICT support and infrastructure, and (2) ICT education and training (see Figure 1). This arrangement will help us to analyze the Tumaini University case study in terms of the contextualization that we shall discuss in section four.

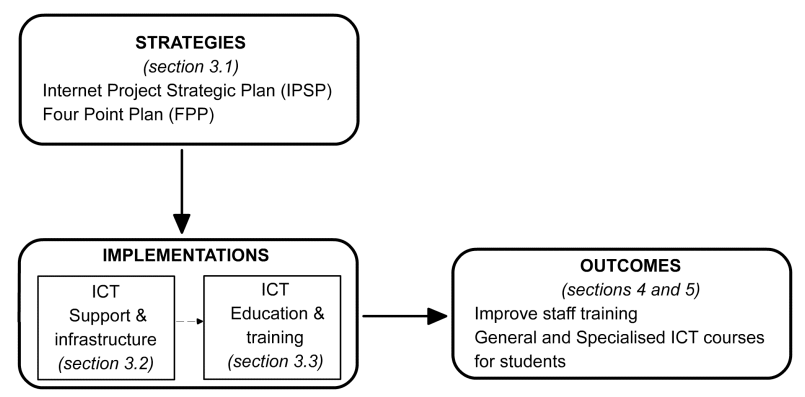

Figure 2: ICT at Iringa University College: From Strategies to Outcomes

\subsection{Strategies}

\section{Internet Project Strategic Plan (IPSP)}

Since 2004 IUCO has been engaged in implementing the Internet Project Strategic Plan (IPSP). This plan defines the general vision, goals, and objectives for all the ICT activities that IUCO plans to establish in its pursuance of an improved learning environment [18]. Because the IPSP vision emphasized the use of the Internet and computers as vital components in an effective learning and teaching environment, IUCO's key task was to get IUCO connected to the Internet.

IPSP arose out of a collaboration between members from FELM, ELCA, and IUCO, and was divided into the following three areas: (1) human resource development, (2) institutional capacity building, and (3) infrastructure development (Figure 3). The aim of human resource

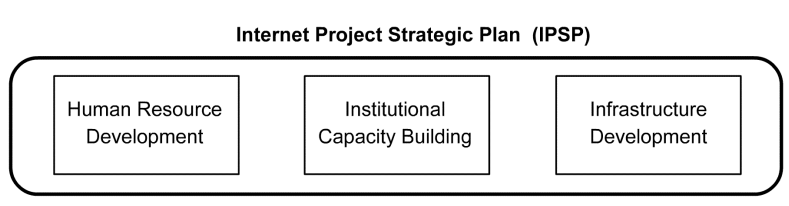

Figure 3: Three Foci of the Internet Project Strategic Plan (IPSP)

development was to train all members of IUCO (faculty, staff, and students) to use ICT facilities in their work as effectively as possible.

Institutional capacity building referred to the development of five areas: the library, curricular exchange, Internet-assisted courses, the Computer Science Department, and language skills. Library development aimed to modernize the catalog system, to establish cooperation with other university libraries in matters such as an interlibrary loan program, to increase the use of CD-ROMs, and to help students to get access to on-line journals, books and databases. Curricular exchange development covered distance learning and curriculum development activities in cooperation with other universities. Internetassisted courses development was focused on providing IUCO students with a distance teaching option that would operate outside of classrooms. Computer Science Department development was predicated on the idea of establishing a new department of computer science. Language skills development included the use of the Internet and CD-ROM technology to enhance student language acquisition.

The third area of IPSP, infrastructure development, covered five initiatives: local linkage, regional linkage, disciplinary consortium, African studies, and local service. The local linkage initiative included cooperation with local educational institutions in activities such as the donation of old computers to local schools. The regional linkage initiative extended the local linkage to other universities and colleges in Tanzania and had the aim to sharing information. The disciplinary consortium initiative covered the same objectives as the regional linkage, but on a worldwide scale. The African studies initiative dealt with the idea of developing an African studies degree program under the faculty of Arts and Social Sciences in cooperation with other African universities. The local service initiative included a plan to start an Internet service provider (ISP) in Iringa and to develop short ICT courses for private clients. 


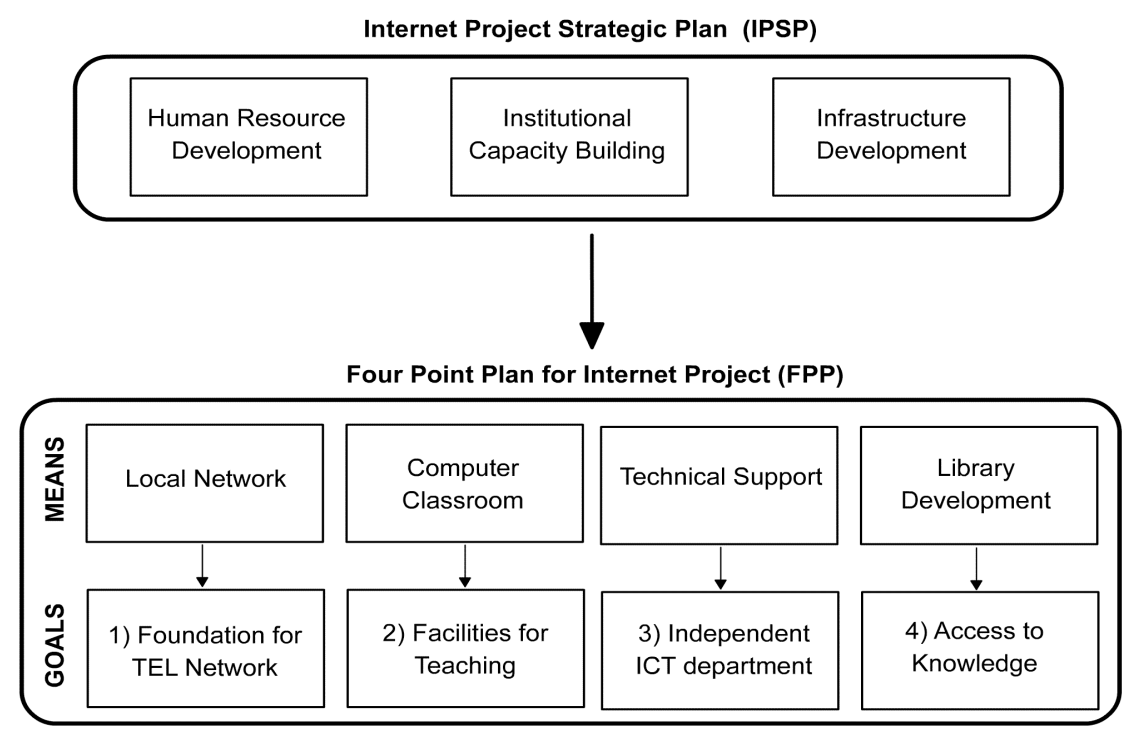

Figure 4: Four-Point Plan (FPP) and Its Implementation Goals for IPSP

The third area of IPSP, infrastructure development - unlike aspects of human resource development and institutional capacity building - was not really ICT-specific. It illustrated instead how ICTs could stimulate favorable developments in content and networking in education at Tumaini.

\section{Four-Point Plan for Internet Project (FPP) as an implementation strategy for IPSP}

The ideas introduced in IPSP on how to use ICT in education were difficult to put into practice because the IPSP strategy was too general. The strategy did not, for example, take into account the lack of ICT facilities other than for Internet connection. Because of this gap between the IPSP strategy and the real ICT situation at IUCO, IUCO devised a new plan entitled Four-Point Plan for Internet Project (FPP) (see Figure 4). This FPP was created after IUCO had analyzed the ICT situation in three other East African universities (University of Nairobi, Sokoine University of Agriculture, and University of Dar es Salaam). The purpose of FPP was to clarify the short-term commitments and determine the priorities of the IPSP. [19]

FPP showed that the college had four aims: (1) Technology Enhanced Learning (TEL), (2) better facilities for teaching, (3) an independent ICT department with its own budget, and (4) access to knowledge for students and faculty. These aims were to be accomplished by (1) the local network, (2) a computer classroom, (3) technical support, and (4) library development.
The local network required the building of a local area network on the campus, connecting all computers to it, and training students and staff in its use. An additional long-term goal (which had already been introduced in IPSP) was to create a solid foundation for technology enhanced learning (TEL). Computer classroom referred to having a new ICT laboratory for teaching. Although a new room had just been built and opened for ICT teaching, the computers were all 486s running Windows 95 and Microsoft Office 95. These were connected by means of temporary LAN wiring and a second-hand HUB. New personnel were to be recruited for technical support to maintain the computers and to offer computer literacy courses. We also recommended to the administration that the university's ICT budget should make provision for one technician for every seventy computers. Library development was intended to solve two existing problems at the library. The first was that computerized catalogues would solve the problem of disappearing books. The second was that CDROM technology and Internet access should compensate for a shortage of learning materials.

\subsection{Implementation: ICT Support and Infrastructure}

The FPP was divided into four separate projects for implementation: (1) IPSP 2001-2003, (2) Internet connection, (3) ICT department and its budget, and (4) the library facilities improvement project (Figure 5). 


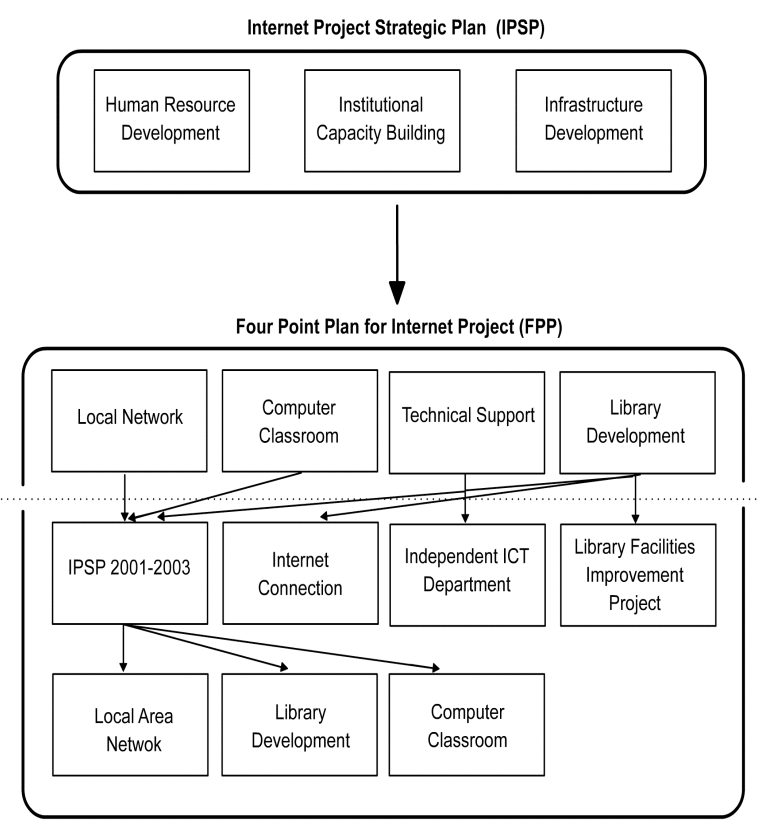

Figure 5: Implementation Plans for FPP as Derived from Its Key Areas

One of these, IPSP $2001-2003^{1}$, included three subprojects. Because the scope of IPSP 20012003 was so wide, it was divided into three independent technical subprojects. The implementation order was based on the expected lifetime of the investments: the LAN wiring was expected to remain in a usable condition for longer than the life span of the new computers. The library management system was also expected to remain in use for longer than the new computers. The final scheme of IPSP 2001-2003 included the implementation plan for three out of the four areas defined in FPP, and these three areas were implemented between the years 2001 and 2003. They proposed:

- to build a LAN in two buildings

- to modernize the library by installing a library management system and by creating the facilities to use CD-ROM learning materials

- to refurbish the ICT laboratory so that it could be used for teaching

The role that an Internet connection would play was originally central to the IPSP, and the importance of an Internet connection is clearly delineated in IPSP's vision and goal. The first part

${ }^{1}$ Note that IPSP 2001-2003 is not the same as IPSP. $I P S P$ is IUCO's overarching strategy that aims at developing the learning environment at the university. IPSP 2001-2003 is a project that implements parts of FPP. of the IPSP consists of an analysis of the state of technical development at IUCO. This analysis is then followed by a consideration of several ways by means of which IUCO could be connected to the Internet. One of these possibilities - the suggestion that IUCO might establish and maintain its own Internet service provider (ISP) in Iringa - seemed both feasible and attractive. After the series of difficulties and challenges described in section four, an Internet connection $(128 / 64 \mathrm{kbs})$ that operated through the landline network of Tanzania Telecommunications Company Limited (TTCL), was eventually established at IUCO in August 2002, and any hope that IUCO might operate its own ISP was put aside for the time being.

An ICT department with its own budget was described as the goal in that part of the FPP that dealt with technical support. This proposal was a crucial subproject of the FPP, and the sustainability of an ICT department was considered to be a key question in the whole project. The development co-operation guidelines of the Finnish Government define sustainability as the "long-term functionality of developed systems" [20]. Sustainability may be said to be assured when the following factors are all accounted for: an adequate and secure economic and financial basis for long-term operation and maintenance; institutional capacity; the capacity to manage whatever systems are in place; sound sociocultural accords and agreements, whether formal or implicit; reliable technical operations, and the maintenance of environmental impacts at an acceptable level. [20] Although there are a number of other definitions for sustainable development, of which the Brundtland Report [21] is perhaps the best known, the definition given here is best suited to our research because we focus on developing education and educational infrastructure.

There were two main obstacles that stood in the way towards the kind of long-term functionality envisaged by the FPP. Firstly, IUCO was not allocating funds for ICT development, and, secondly, IUCO had not organized ICT department. Possible solutions to both of these problems had been under investigation since the earliest stages of the project. IUCO administration then took two measures to compensate for the lack of funds. Firstly, the administration included in the university budget of 2002-2003 provision for the maintenance of ICTs [22]; secondly, they began to charge students a computer access fee for computer tuition. The major problem posed by the absence of an ICT department proved to be much more difficult to solve. There are very few qualified ICT professionals in Tanzania, and especially in Southern Tanzania. In the academic 
Table 4: ICT Resources Available for IUCO Students and Staff (1999 and 2004)

\begin{tabular}{|c|c|c|c|c|}
\hline \multirow{2}{*}{ Resource } & \multicolumn{2}{|l|}{1999} & \multicolumn{2}{|l|}{2004} \\
\hline & Students & Staff & Students & Staff \\
\hline Computers & $30(486)$ & $18(486)$ & 73 (37 P4, 36 586) & 72 (12 P4, 60 586) \\
\hline Server Computers & none & none & 2 & 1 \\
\hline Printers & 4 matrix & $\begin{array}{l}6 \text { matrix and } 1 \\
\text { ink-jet }\end{array}$ & 2 laser & $\begin{array}{l}2 \text { laser, } 6 \text { ink-jet, } \\
\text { and } 4 \text { matrix }\end{array}$ \\
\hline $\begin{array}{l}\text { Data/Video } \\
\text { Projector }\end{array}$ & none & none & 1 & 3 \\
\hline ICT Laboratories & 1 & none & 3 & none \\
\hline $\begin{array}{l}\text { ICT Teaching } \\
\text { Laboratory }\end{array}$ & $\begin{array}{l}1 \text { (14 } \\
\text { computers) }\end{array}$ & none & 1 (21 computers) & none \\
\hline Internet Laboratory & none & none & 1 & none \\
\hline ICT Service Centre & none & none & 1 & none \\
\hline ICT Service Rooms & none & none & none & 2 \\
\hline
\end{tabular}

Table 5: Common ICT Resources at IUCO in 1999 and 2004

\begin{tabular}{|l|l|l|}
\hline \multicolumn{1}{|c|}{ Resource } & \multicolumn{1}{|c|}{$\mathbf{1 9 9 9}$} & \multicolumn{1}{c|}{2004} \\
\hline Internet Connection & none & $128 / 64 \mathrm{~KB}$ \\
\hline Server Computers & none & 4 \\
\hline Computer Centre & none & 1 \\
\hline Maintenance Room & none & 1 \\
\hline Staff & 1 & 8 \\
\hline
\end{tabular}

year 2002-2003 the problem of ICT support and maintenance became much more critical when the last voluntary ICT teacher from abroad left the college. Although no official ICT organization existed at IUCO before 2003, there were two Tanzanians who worked with ICT in the academic year 2002-2003. One of these was an ICT teacher who worked for the university on an hourly basis. The other was a former secretary who had one year of ICT education.

The implementation of ICT support and infrastructure was based on the prioritized key areas of FPP. Table 4 and Table 5 show the increase in ICT resources between 1999 and 2004.

The library facilities improvement project was the fourth subproject of the FPP. Its aim was to supplement scarce print material in the library by means of electronic media such as the Internet and CD-ROMs. Since the implementation of this project is not part of the topic of this research paper, we shall omit any further consideration of it at this point. 


\subsection{Implementation: ICT Education and Training}

Table 6, compiled from the course outlines and prospectuses of IUCO [23], shows the history of ICT education at IUCO. There are eight courses that focus mostly on computer applications. All of these courses were taught in the academic year 2004-2005. The four foundational courses, Information Technology I, Information Technology II, Information Technology (Journalism), and Information Technology (Business), remained basically the same between 1999 and 2004. Four newer courses were launched by the Department of Education at the beginning of the academic year 2002-2003. These were Instructional Technology in Mathematics Teaching, System Support and Administration, Introduction to Computer Networks, and Computer Programming. connection to the Internet itself. Teachers had to save all instructional material to a file, print it out on paper, or else show it to all the students together from one small computer screen because there was no data projector. By 2004 the ICT laboratory was connected to the Internet. Both software and hardware were up to date, and a data projector was a part of the equipment.

ICT training has been addressed by annual ICT courses for staff that have a strongly practical bias [22]. These courses covered the same issues as did basic courses for students. They taught basic office applications such as Word, Excel and PowerPoint, as well as some basic Internet skills such as sending and receiving email and searching for information. Between 2002 and 2004, IUCO's ICT trainers also developed and presented a series of courses for the staff and faculty. In 2003, for example, the Department of

Table 6: ICT-related Courses at IUCO

\begin{tabular}{|l|c|c|l|}
\hline \multicolumn{1}{|c|}{ Course } & $\begin{array}{c}\text { Introduced } \\
\text { (year) }\end{array}$ & Target & \multicolumn{1}{|c|}{ Remarks } \\
\hline Information Technology I & 1994 & All students & Reviewed 1999 \\
\hline Information Technology II & 1994 & All students & Reviewed 1999 \\
\hline Information Technology - Journalism & 1998 & Journalism & Reviewed 1999 \\
\hline Information Technology - Business & 1998 & Business & Reviewed 1999 \\
\hline $\begin{array}{l}\text { Instructional Technology in Mathematics } \\
\text { Teaching }\end{array}$ & 2002 & Education & \\
\hline System Support and Administration & 2002 & Education & \\
\hline Introduction to Computer Networks & 2002 & Education & Education \\
\hline $\begin{array}{l}\text { Computer Programming / } \\
\text { Contextualized Programming Course }\end{array}$ & 2002 I & $\begin{array}{l}\text { Renewed 2004, } \\
\text { Research } \\
\text { Project }\end{array}$ \\
\hline
\end{tabular}

While most of the courses were quite traditional in design and intent, the System Support and Administration course was designed for student teachers who might in the future need to work with an inadequate ICT infrastructure such as that which is powered by current generated by solar panels for laboratory electricity.

Although there have been no major changes in courses, teaching facilities improved significantly between 1999 and 2004: 486 computers were upgraded to Pentium 4 computers, and Windows and Office were upgraded from 95 versions to XP versions. In 1999 the students were being taught how to use Internet facilities such as search engines and email without any real-time
Journalism offered two courses in web publishing, one for faculty and the other for students. Both these courses were designed to give those attending an understanding of the structure, layout and management of a website. The course content and activities were alike for both groups and included the explanation of concepts such as hypertext, pixel/vector graphics, editors, animations and interaction. Course activities included an analysis of existent websites.

Since IUCO offers no degree program in ICT, courses are nearly always related to computer applications, and computer science courses are rare. Computer programming, the course that is most typical of a computer science degree 
syllabus, was introduced in 2002. The method of teaching the course before 2004 was strongly based on the kind of teaching method one would find in Western universities where most of the students have already had extensive experience of ICTs of one kind or another even before their university studies commence. The course content was also out of date. Thus, for instance, programming was being taught by means of Qbasic. A more recent pedagogical strategy has been to teach a large number of difficult concepts such as trees and stacks by using $C$ language [24]. One cannot help noticing that because students were being taught data structures and algorithms even before they had any knowledge of even basic programming concepts, the chance of them having learned anything beyond what they could memorize by rote without any real understanding was unfortunately close to nil.

IUCO was interested in continuing to develop ICT education on the basis of the program outlined by IPSP, and collaboration with foreign institutions was already well established. In 2004 IUCO introduced a contextualized programming course for B.Ed. students in collaboration with the University of Joensuu (Finland) and the University of Southern Denmark. The course featured problem-based learning and made use of local examples, project work, interaction between university and school students. There was also a strong emphasis on activating tools such as robotics and visualization. The idea was to encourage the students to contextualize their emerging ICT skills in their everyday context, and to use creative problem solving to apply knowledge and skills simultaneously within a familiar context. [25]

\subsection{A Summary of the IUCO Case}

A comparison between the Four-Point Plan (FPP) and the implemented projects shows that the key areas of FPP and its short-term objectives were implemented during years 2000-2004 (Figure 6). IUCO modernized ICT laboratory for teaching (facilities for teaching in FPP), implemented LAN (foundation for TEL network in FPP), and acquired an Internet connection and a library system (access to knowledge in FPP). IUCO also established an ICT Department and allocated money for ICT in IUCO's annual budget (ICT department and budget in FPP). Two objectives of FPP were, however, not met. Firstly, IUCO did not establish a local Internet service provider because it would have demanded resources that IUCO did not have (original assets and human resources), and because at that time other ISPS had already become operational. Secondly, IUCO has not yet begun to offer ICT courses to outsiders because of the shortage of ICT staff at the college.

\begin{tabular}{|c|c|c|c|c|c|c|}
\hline YEAR & $\begin{array}{c}\text { STUDENT } \\
\text { BODY }\end{array}$ & & & & & \\
\hline & & \multicolumn{5}{|c|}{ Internet Project Strategic Plan } \\
\hline 2000 & 240 & $\begin{array}{c}\text { IPSP } \\
2001-2003\end{array}$ & $\begin{array}{c}\text { Fr } \\
\text { Internet } \\
\text { Connection }\end{array}$ & $\begin{array}{l}\text { PPP } \\
\text { Independent ICT } \\
\text { Department }\end{array}$ & $\begin{array}{l}\text { Library Facilities } \\
\text { Improvement Project }\end{array}$ & $\begin{array}{l}\text { peration with the } \\
\text { ersity of Joensuu } \\
\text { gins unofficially }\end{array}$ \\
\hline 2001 & 350 & $\begin{array}{l}\text { Computer } \\
\text { Classroom }\end{array}$ & & & & \\
\hline 2002 & 455 & $\begin{array}{l}\text { Local Area } \\
\text { Network }\end{array}$ & $\begin{array}{l}\text { The first } \\
\text { computer gets } \\
\text { a connection }\end{array}$ & $\begin{array}{c}\text { The budget } \\
\text { for ICT }\end{array}$ & & 1 \\
\hline 2003 & 580 & $\begin{array}{l}\text { Library } \\
\text { Development }\end{array}$ & $\begin{array}{l}\text { All computers } \\
\text { have a } \\
\text { connection }\end{array}$ & ICT department & $\begin{array}{l}\text { Co-operation } \\
\text { agreement with } \\
\text { the University of } \\
\text { Joensuu signed }\end{array}$ & $\begin{array}{l}\text { Co-operation with the } \\
\text { University of Southern } \\
\text { Denmark and some local } \\
\text { secondary schools begins }\end{array}$ \\
\hline 2004 & 670 & $\begin{array}{l}\text { LAN extension, } \\
\text { Internet and } \\
\text { media laboratory }\end{array}$ & & & $\begin{array}{r}\text { The first } c \\
\text { program }\end{array}$ & iming course \\
\hline
\end{tabular}

Figure 6: An Overview of the Projects Derived from IPSP and the Number of Students (by year) 


\section{Analysis}

The contextualized approach to ICT in higher education can be represented as two parallel but opposite processes: planning and implementation (Figure 7). Our contextualized approach is based on our experience of carrying out the IPSP and other projects in Tanzania [6],[25-30]. We use the four levels CATI model - contextualize, apply, transfer, import - to analyze the planning and implementation processes (especially from the troubleshooting and constraints points of view). The planning process proceeds from contextualization to import, and the implementation process proceeds from import to contextualization.

It is important to note that the planning and implementation processes can interact with one another on all levels, and that the CATI model can be used with subprojects in continuous processes like the circle in Figure 7. A scheme of apply transfer - apply would make sense in a situation model by considering the dictionary definitions of the terms import, transfer, apply, and contextualize. The dictionary we use [31] gives the following meanings for the four key words:

Import to bring or carry in from an outside source, especially to bring in from a foreign country for trade or scale

Transfer to convey or cause to pass from one place, person, or thing to another

Apply to bring into nearness or contact with something; put on, upon, or to put into action

Con- to place (e.g., a word or an idea) in a textualize particular context, where context refers to the set of facts or circumstances that surround a situation or event; "that which surrounds and gives meaning to".

We can now extrapolate meanings that are

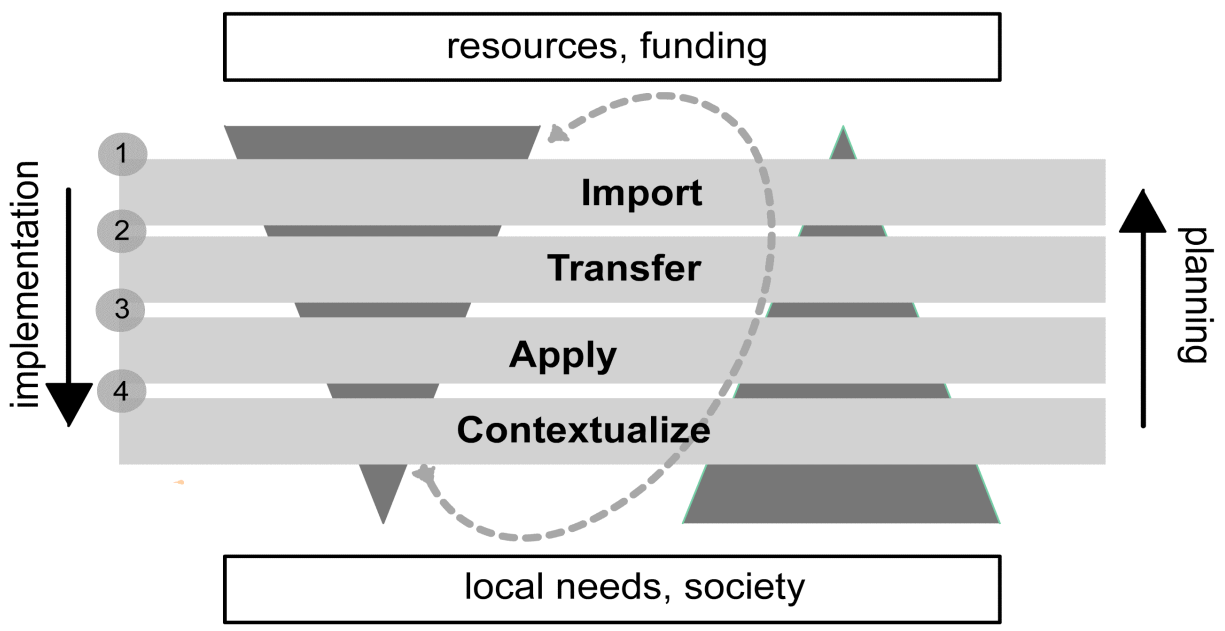

Figure 7: The Four-Level Model for Representing and Analyzing the Planning and Implementation Processes of ICT.

where planning starts from an identified need of a particular application, which needs to be transferred for a user who needs to learn to use the application.

The four-level model is a simple framework that provides practical descriptors or benchmarks that researchers and providers can use to identify the difficulties that arise from the use of ICTs in developing countries and to analyze the cause of such difficulties. The planning and implementation processes are visible in both of the two roles that ICT plays in a higher education institution: ICT support and infrastructure, and ICT education and training (see Figure 1 and Figure 2). We embark on our definition of the levels in the four-level specifically relevant to ICT for each of these words. Note that ICT refers here to any kind of software, hardware, wiring, service, innovation, idea, and so forth.

Import The technological applications of ICT (hardware and software) are available on site. But warmware - human knowledge and experience - is missing.

Transfer Human and technological ICT resources become available to those who need them through transference. Most resources are transferred from outside a community into the community. 
Apply ICT resources are used or mobilized in action. A user can apply ICT to the task that for which it has been invented. The application of resources often happens in a context other than that for which resources were originally designed.

Con- ICT will only fulfill the needs of the local textualize community only if ICT is adapted, appropriated, re-invented [32] and implemented in a way that enhances the local context.

From the local point of view, we can expand these terms in the following way:

Import Imported things may be innovations such as tools, books or attitudes. All of these may be very useful and needed in themselves or in their original context. But mere importation here means receiving something from abroad without any prior analysis of local needs. This kind of importation means creating a strong possibility of nonsustainable development.

Transfer While transferred goods or human capital may be accessible to their users and even potentially applicable in a local context, the accompanying analysis of local needs may be relatively weak.

Apply In application the potential of transferred things and human capital are realized. This kind of use is not simply mechanical. Creative application requires the users' own initiative. Effective application requires basic contextual expertise. A user can thus apply office applications for his or her own purposes (e.g. assignments, project reporting) without a more extensive relevance to his or her environment.

Contextualize Contextualizing is intrinsically related to the needs of the larger user community. Contextualized ideas or technology relate directly and effectively to the needs of a certain sociocultural context or environment. The one who performs this is from the area itself, and the need for the analysis is rooted in that area. Because of the tight bonds between a community's people and its needs, contextualized innovations have a far better chance of sociocultural sustainability than do applied innovations.

This four-level CATI model can be utilized for:

- developing sustainable ICT solutions in collaboration between developed and developing countries

- analyzing the planning and implementation processes of ICT

- evaluating a person's ability to apply learned knowledge in an educational setting

What follows below is an analysis of the planning and implementation of the project at IUCO that we described in section three. We will pay particular attention to the problems that we encountered on the way - especially those that hindered a shift from one level onto another. Several problems were caused by technology-driven implementation that took place at the expense of context-based planning. In our case, our starting point was the expertise that was available among the Tumaini University staff. We used their IPSP and FPP analyses as our basis for development.

\section{Planning}

Figure 8 labels the FPP strategy that we described in section three as a planning process in the four-level CATI model (the planning process is marked by the arrow on the right hand side of Figure 7). The FPP strategy was born at the moment when the staff at Tumaini University accepted that they wanted to be able to utilize ICTs in education. The FPP started in Tanzania, in Iringa region, at Tumaini University - all these places define the context (4). The planning was then carried out by applying (3) the ideas in FPP (see Figure 4). This resulted in the division of FPP into four subprojects. These subprojects were: IPSP 2001-2003, Internet connection, ICT department, and Library facilities (Figure 5). The process continued with transferring (2): this is a movement from ideas to practical plans. The last phase was evident in the need to import (1) infrastructure and funding. Both needs were concretized in 2000 as a funding application. 


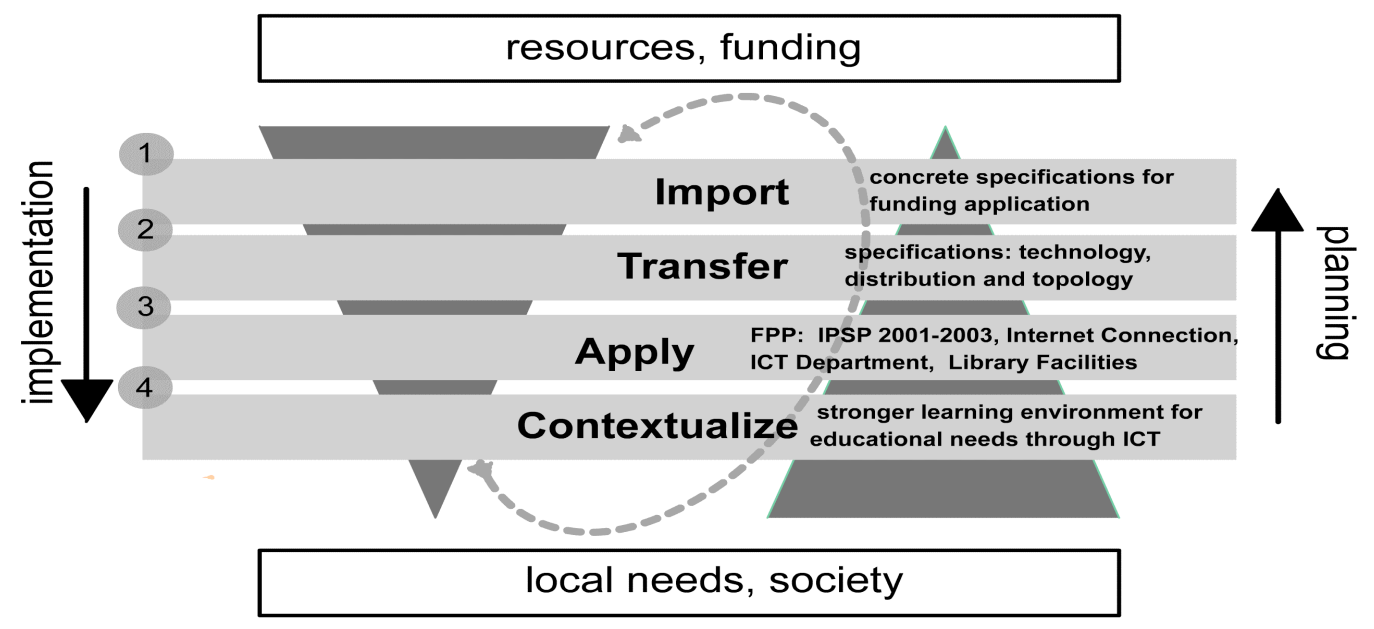

Figure 8: Planning of Four Point Plan (FPP) to Use ICT at IUCO

In the subsections that follow, we continue to analyze the implementation of FPP's four subprojects (IPSP 2001-2003, Internet connection, ICT department, and library facilities) on the implementation side of CATI model (the implementation process is marked by the arrow on the left hand side of Figure 7). us to exercise patience because certain (often unexpected) difficulties such as long waits for the required materials are simply part of the reality of everyday working transactions in a developing country. But, even then, once we had got hold of the right technologies and material, we found that they could not be transferred (2) into use or operationalized immediately because of a number

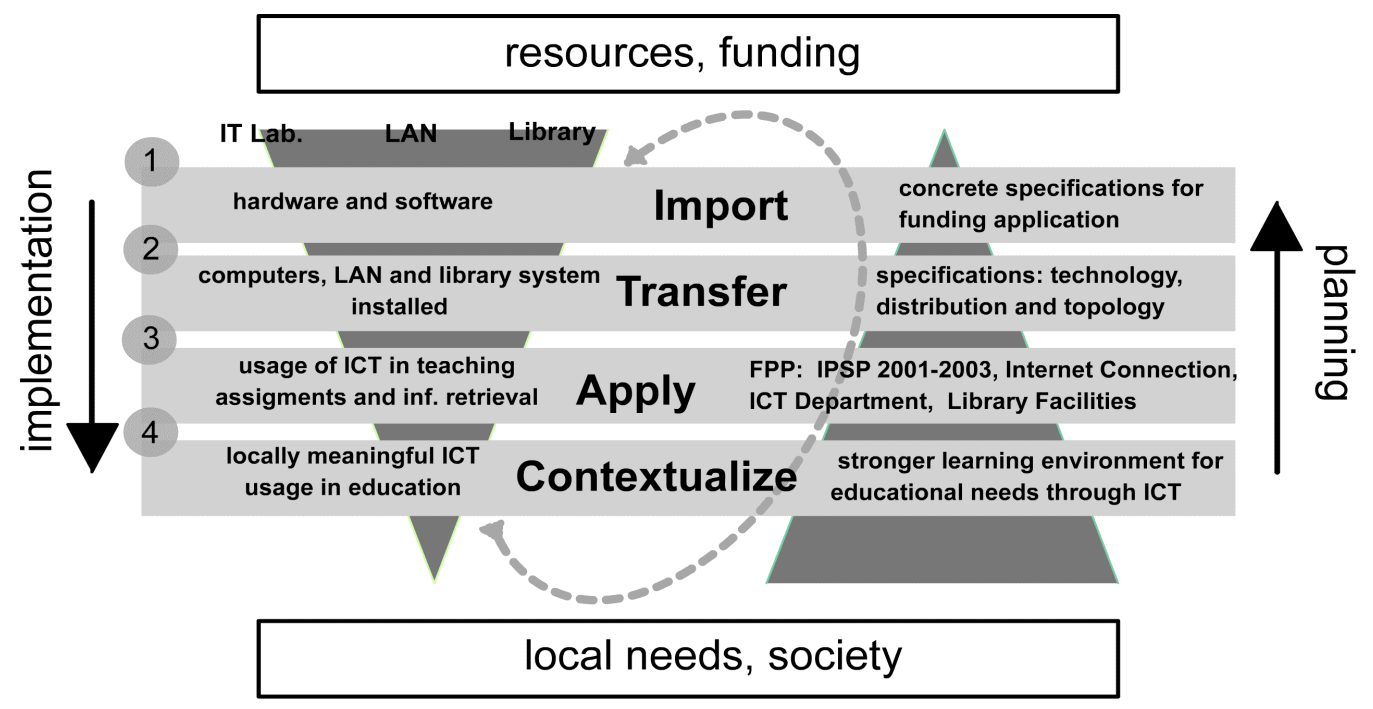

Figure 9: Implementation of IPSP 2001-2003

\section{Analysis of FPP subproject 1: IPSP 2001-2003}

Although the planning of IPSP 2001-2003 was carefully carried out, the implementation process was accompanied by several problems. The project required us to set up an IT laboratory, build a local area network (LAN), and develop the library facilities. The first problem that we encountered in the implementation of IPSP 20012003 (Figure 9) was on the import level (1). The problem was that it was difficult to obtain the right materials and machines. This problem compelled of practical reasons. The desks, for example, were not strong enough; water gushed into the building from outside; the earth leakage electrical system did not work; power cuts were frequent; there were no local fiber optic cable or companies with the necessary skills who could perform maintenance, supply spares or offer expert advice; the cooling system was inadequate, and so on. These problems are typical of developing economies. But once again, we solved these problems by exercising our imagination and by 
taking local conditions and possibilities into account. Before they could apply the ICT (3) that they had acquired, the staff needed to be educated. Fortunately, there were a number of
Internet connection within four months. But our timetable was too optimistic because there were no suitable ISPs available in the region. This caused a two-year delay at the import (1) level

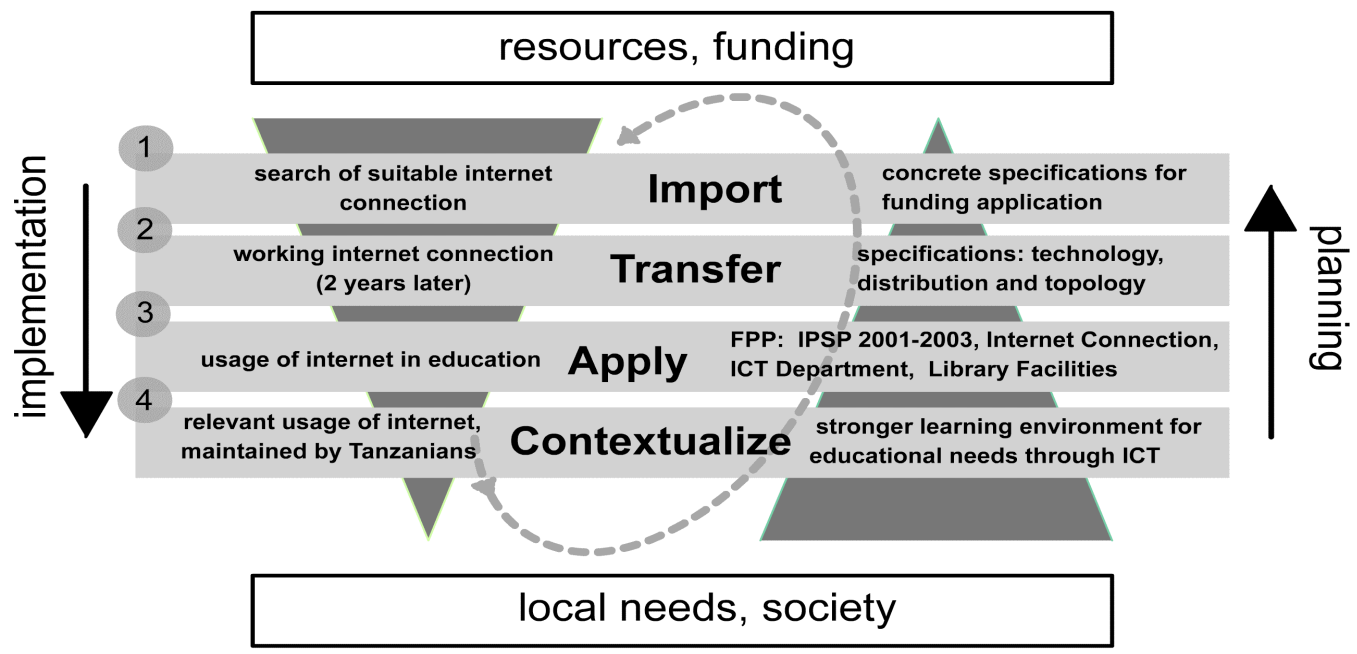

Figure 10: Implementation of the Internet Connection

courses for the staff that imparted computer literacy. These are noted in IPSP's human resource development: see IPSP in Figure 3. Contextualization (4) required us to exercise a great deal of imagination and ingenuity in our consideration of the local context. This level was at least conceptually met by the contextualized programming courses that we started at IUCO in 2004. These courses are the first components of a contextualized B.Sc. degree program in ICT.

\section{Analysis of FPP subproject 2: Internet connection}

Our intention in the beginning was to set up the
(Figure 10). After two years had passed, ISPs were offering ADSL connections in the area at a reasonable price. Even so, the connection was not satisfactory. We had a problem at the transfer level because of the slow speed of the ADSL and also because of frequent interruptions to the connection (2). But the reliability of the connection gradually improved, and eventually, in some Internet-related classes, the local server was able to maintain a stable Internet connection.

When we reached the application level (3), we found that the number of Internet users was growing more quickly than bandwidth (128/64 $\mathrm{KB})$. The cost of Internet connection also

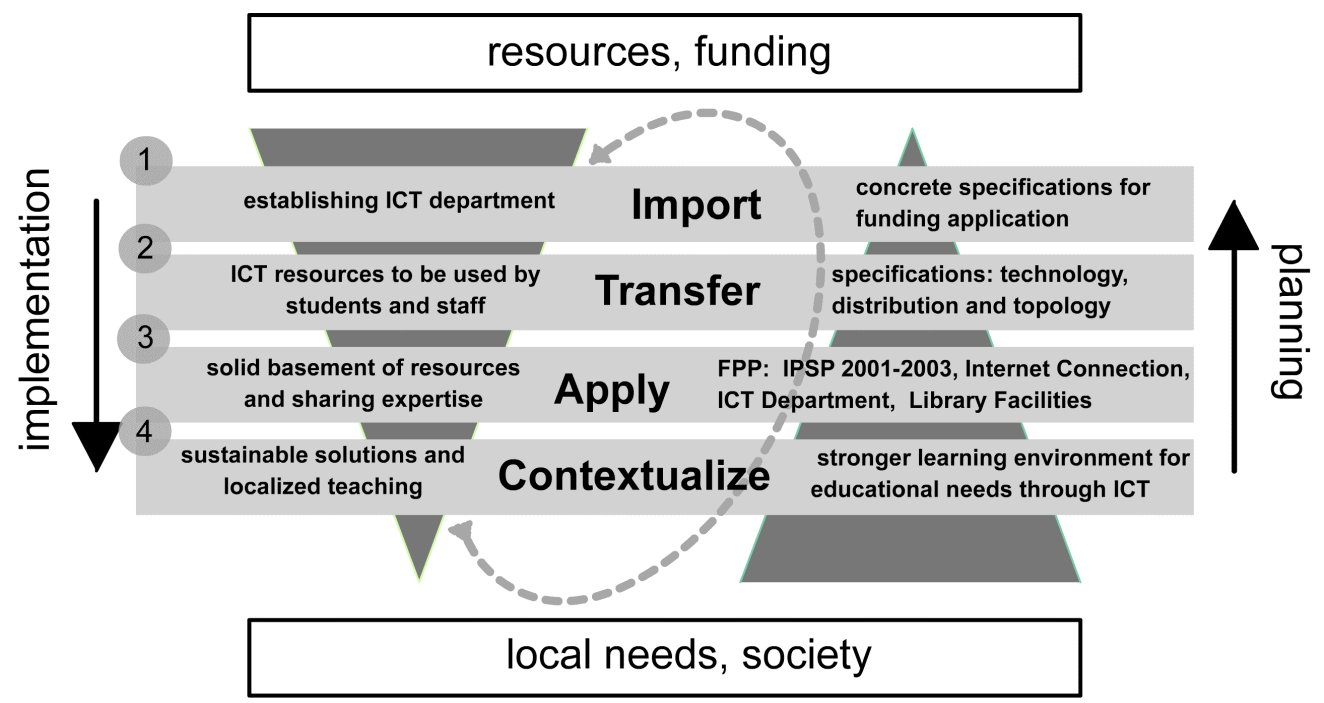

Figure 11: Implementation of ICT Department and Its Budget 
remained high. Despite these continuing difficulties, the newly functioning Internet connection gave us opportunities to undertake relevant teaching to access necessary information (4). Such activities were among the main goals of the IPSP project. A number of IUCO's departments also at this time began to experience substantial benefits. Thus, for example, the Department of Business began regularly to get access to real-time information about national and international businesses; the Department of Journalism began to get access to national and international papers, magazines, and other media, and the Department of Education began to get access to databases and e-libraries. And by 2004 the LAN was being maintained by IUCO staff and by technicians from TTCL, a local Tanzanian company.

\section{Analysis of FPP subproject 3 : the ICT Department and its budget}

In the early days of the project, the ICT Department was being run only by temporary staff. The department also had no solid funding on which it could rely. It became apparent to us that if sustainable development were to take place in the ICT Department, it would have to be properly organized. Obtaining (1) external funding and employing regular staff would open for IUCO opportunities to transfer (2) the technology that IUCO needed to function properly (Figure 11). knowledgeable and capable staff members made the practical application of technology possible (3) (Figure 11). We found however that the new staff was not committed to innovative approaches to the teaching of ICT courses that were relevant to the local sociocultural context (4) because the local approach to education seemed to be based on modified nineteenth century Western models. In addition to this, the institution was also then not offering a competitive working environment, salaries or career opportunities.

\section{Analysis of FPP subproject 4: Library Facilities Improvement Project}

The Library Facilities Improvement project was the least ICT-intensive part of FPP. There again, the library project was strongly linked to the information needs of IUCO. The first part of the project involved the importation of second-hand books from abroad (1) (see Figure 12). Although this greatly expanded the library's book collection, some of the imported books were outdated or irrelevant. The consequence of this was that departments were asked to propose lists of the books that they needed so that they might benefit more specifically from the library as a resource. This represented transference of the benefits of the resources to those that needed them (2). The subsequent use of books in different fields of education moved the process onto the application level (3). It is pertinent at this point to ask how

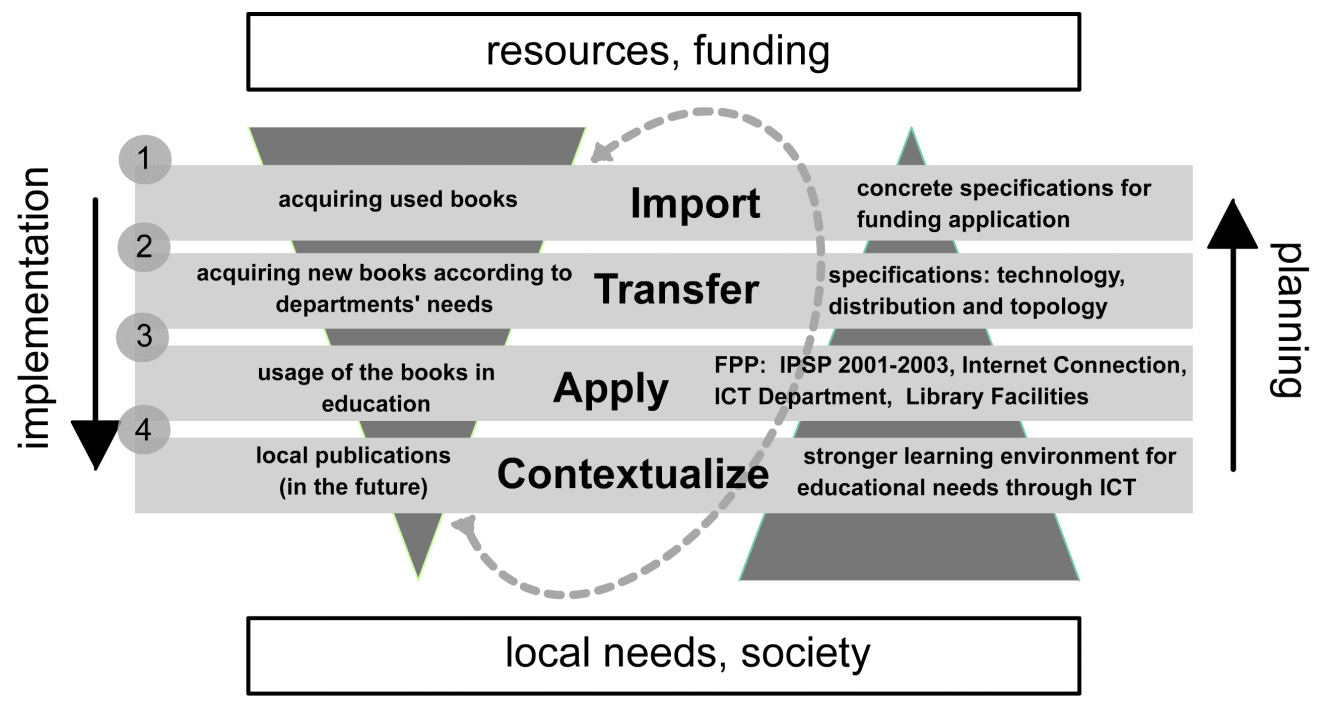

Figure 12: Implementation of the Library Facilities Improvement Project

The shortage of staff was remedied when the department obtained the services of a few Tanzanians who had been educated in Western countries. This employment of trained, contextualized or relevant the material was. When students begin to use library resources for their own needs, library services begin to approach the contextualization level (4). 


\section{Universal or Particular?}

One of the main sticking points in the debate about technological development is the juxtaposition of universal and particular (this is also visible also in the above-mentioned technology-oriented $v s$. community-based development debate). This juxtaposition takes different forms in different contexts. In debates about the role of education, lines are often drawn between pure and applied, scholarly and professional, theoretical and practical, academy and industry, and abstract and concrete. The same antinomies are also evident in debates about knowledge - about whether knowledge is universal or particular, global or local, objective or subjective, transcendent or situated.

This debate is also central to our work. As we worked with the technologies and technological education that supports Tanzania's Vision 2025, we were constantly faced with questions such as, "Which elements and aspects of technology and education should be localized? Which should not be localized? Which elements of local knowledge contribute to our own understanding of technology and education?" Like most practitioners operating in this field, we have adopted an intermediate position between these two poles: we believe that a considered dialectic between universal and local creates a viable synthesis.

During our work in Tanzania, we gained a great deal of insight into the world of Tanzanian students, the university administration, as well as local and national government. Our experience leads us to maintain the position that it is imperative for us not to present computing merely as a scholarly, theoretical, and abstract activity that is removed from any kind of context. We also do not focus only on tools (i.e. on the practical, concrete, and the applied). Throughout this project we constantly sought a balance between the theoretical and practical, a balance that we believed would satisfy all parties equally.

In support of the national Vision 2025 and IUCO's strategies we built local networks and computer classrooms. This first aim - the construction of infrastructure - made it clear to us that it was important for us to understand the theoretical aspects of ICT while at the same time being able to adapt to and harmonize with local conditions. It is not enough simply to know how to build a computer laboratory. One also has to understand and be able to accommodate oneself to local customs and modes of operation in matters such as appropriate and reliable channels for funding, the levels and social meaning of bureaucracy, the ways in which local people organize themselves, channels of influence, risks and possibilities, strategic emphases, limited resources, and degrees of sustainability and commitment.

Our work in realizing our role in the second part of the major visions and strategies, human resource development, began with developing appropriate levels of ICT literacy in the faculty and students. Teaching basic computer literacy is a demanding task in a developing country, and we had to learn how to make the necessary compromises and adjustments along the way. Students and faculty in general had very little experience or understanding of any kinds of advanced technological equipment such as computers and their peripherals. Instead of imposing some kind of "universal approach", or simply trying mechanically to transfer the content of some elementary textbook about computers, we supported the local approach by starting with a consideration of the needs of the students and the faculty.

We therefore approached the situation by working together with students and faculty firstly to identify and analyze the problems that faced us (by reference to the analyses made earlier by IUCO). Secondly, we identified the technical tools that would be appropriate for a solution of the problems that had been described. Thirdly, we enumerated the kinds of skills that would be needed for the various tasks that were facing us. We continued to defer respectfully to the local approach by accepting that teaching should not be merely theory-oriented imposition but that it should rather reflect a judicious combination of practical concerns and the subject matter that would be needed by students and teachers. Only once these matters had been settled did we give the theoretical implications of these practical issues the consideration that they needed.

Here we hit another series of problem. Because of Tanzania's severe shortage of ICT professionals, we had to extend our range of teaching from computer literacy courses to courses in computer science because theory is indispensable to an understanding of computer science. In spite of this faultless analysis, the same question confronted us when we came to teaching computer science: should our teaching be pure or applied, theoretical or practical? Or, more specifically, what combination of both would respect local custom but yet support the unavoidable needs of the teaching process? A solution was closer to hand than it might otherwise have been because together with many authorities in the field of computing, such as Knuth, 1991 [33], we believe that abstract and concrete considerations are inextricably linked in the teaching of computer science. We consequently emphasize the fact that ICT 
professionals constantly face not only theoretical and technological limitations, but also economic, ecological and geographical limitations - not to mention cultural, social, and philosophical barriers [30]. While theoretical and technological limitations may be universal and non-culturally specific, the other limitations are very real too, and ways to cope with them cannot be learned from textbooks.

Our goal was (and is) therefore to teach computer science that has meaning, programming that is based on sound empirical premises, and problem solving that is concerned with real problems [34]. Both content and context are important in ICT education. Content represents pure, scholarly, global and theoretical considerations while context represents the applied, the professional, the practical and the local. Content is hardware, context is the uses to which hardware is put. We believe that if technology, technological knowhow, computer applications, and ICT education are all imported and uncritically accepted, the country that imports them will remain on a digital leash as a mere consumer of ICT. An uncritical acceptance of foreign technology is precisely the syndrome that has given rise to concerns about some of the more deleterious and sinister aspects of the process of globalization.

In contrast to being solely an uncritical importer, Tanzania could, if it were to nurture local means of production and local talent, become a country that develops ICT-specific education and a culture of ICT that is peculiarly Tanzanian in spirit and identity. In the process, it could also support local development, contribute to meeting WSIS goals, and create for itself a role as a producer of and contributor to ICT. One need not locally produce all that is needed for computing. It would be folly to attempt to compete in an already saturated international hardware markets. But if it were to bypass hardware production and move directly on to less material modes of production, Tanzania could well gain a share in global markets.

In we will continue our work in future by retrospective analysis of the skills that students have learned during the computer science courses. Our main focus in that case will be on the application of ideas and the skills that students invent and learn during or after the courses. This will give us important information about the future development of computer science education in Tanzania and in any other developing country. It will also guide us as we continue to remain interested in the development of a local (Tanzanian) degree in ICT.

\section{Conclusions}

In this paper we sketched the development of ICT usage and ICT education at Iringa University College of Tumaini University between the years 2000 and 2004. During this time, the utilization of ICTs and ICT education evolved from a shadowy half-existence to being the pride and showpiece of the college. The university has contributed to this success by allocating steady funding from its budget for ICT concerns. It has also succeeded in obtaining sustained external funding for maintenance and development. The functional and practical ICT know-how that students are currently offered prepares them not only for the Tanzanian labor markets, but also for global information sources and global markets.

The most important lesson that this project has taught us is the indispensability of local knowledge. Much of the knowledge that the success of this research has been based on is tacit, unspoken knowledge of the researcher, knowledge that has come together during years of living within the community. Yet there is a lot of overt knowledge too, knowledge that can be transferred to other similar projects. Examples of this sort of overt knowledge are, for instance, the necessity and difficulty of finding even slightly qualified people for support and maintenance, not to mention ICT teachers; the importance of getting a firm commitment from different levels of the university; and the locally built sustainability for the project: In order to be worth the investment, most of the development projects have to eventually become autonomous and selfreproductive.

Iringa University College's successes in the development of ICT support and infrastructure as well as ICT education and training, its continuous channels of funding, ongoing human resource development, co-operation agreements, and its production of own, contextualized ICT-courses are all indicators of a very strong tendency towards autonomy and self-sustainability. Because the development steps taken during this project have all been locally managed and not imposed by outside experts, sensitivity to the world of the students and faculty has been maintained. Furthermore, neither teaching nor planning have been based on standard Western strategies, but on local skills, attitudes, values, knowledge, as well as local limitations. As such, the teaching and planning both have a much better sociocultural fit than an imposed "standard" or "mainstream" strategy would have had.

Our experience with this project has led us to propose a four-level CATI model for ICT planning, evaluation, and training in developing countries. 
These four levels, contextualize, apply, transfer and import, constitute three aspects of the ethnocomputing of a particular sociocultural setting: representation, utilization, and appropriation [35]. Representation consists of aspects such as conceptual models, mental models, and methods of teaching; Utilization includes aspects such as uses of technologies, diffusion patterns, and social attitudes towards technology; Appropriation involves aspects that break the mainstream mental models, such as using technology for non-standard purposes, jobcreation through innovative business ideas, and the creation of ad-hoc solutions for technological obstacles.

We believe that an interaction between the implementation and planning-aspects of our approach can significantly help projects to achieve results that are sustainable, relevant, and autonomous as well as effective, productive, and influential. After all, no technology is ever used in a sociocultural vacuum: The power and significance of hardware and software comes from warmware, from people, from the fact that technology can help people in some way or another. If an ICT project lacks the know-how of implementation, progress is hard to achieve - and if a project lacks relevance in planning, seeming progress may not improve anything. But an insightful combination of implementation and planning can result in a real, decisive improvement in people's lives.

\section{Acknowledgment}

This study has been supported by the Academy of Finland: Information and Communication Technology Education for Development: a Tanzanian Perspective (201682) and Centre for International Mobility (CIMO).

\section{References}

[1] Geneva Declaration of Principles (2003) World Summit on the Information Society, WSIS. URL: http://www.itu.int/wsis/docs/geneva/official/dop.ht $\mathrm{ml}$ (Jan 19, 2006)

[2] Geneva Plan of Action (2003) World Summit on the Information Society, WSIS. URL: http://www.itu.int/wsis/docs/geneva/official/poa.ht $\mathrm{ml}$ (Jan 19, 2006)

[3] United Nations General Assembly (2000) United Nations Millennium Declaration. URL: http://www.un.org/millennium/declaration/ares552 e.pdf (Jan 10, 2006)

[4] Suárez, J. (ed.) (2005) Social Watch Report
2005: Roars and Whispers. Instituto del Tercer Mundo, Montevideo, Uruguay.

[5] Avgerou, C. (2002) Information Systems and Global Diversity. Oxford: Oxford University Press.

[6] Sutinen E. \& Vesisenaho, M. (2005) ICT Education in Tanzania: A Contextualized Approach, in Proceedings of the $11^{\text {th }}$ International Conference on Human-Computer Interaction International (HCII) 2005, 22-27 July 2005, Las Vegas, USA.

[7] UN Office of the High Representative for the Least Developed Countries, Landlocked Developing Countries and Small Island Developing States (2006) List of Least Developed Countries. URL: http://www.un.org/specialrep/ohrlls/ldc/list.htm (Jan 19, 2006)

[8] Tedre, M.; Sutinen, E.; Kähkönen, E. \& Kommers, P. (2006) Ethnocomputing: ICT in Social and Cultural Context. Communications of the ACM 49(1):126-130.

[9] Mkude, C.; Cookset, B. \& Levey, L. (2003) Higher Education in Tanzania: A Case Study. Oxford and Dar es Salaam: Partnership for Higher Education in Africa Series, James Currey Ltd. and Mkuki na Nyota,

[10] Planning Commission (1999) The Tanzania Development Vision 2025. The United Republic of Tanzania. URL:

http://www.tanzania.go.tz/vision.htm (Jan 19, 2006)

[11] Ministry of Communications and Transport (2003) National Information and Communication Technology Policy. The United Republic of Tanzania. URL:

http://www.tanzania.go.tz/pdf/ictpolicy.pdf (Jan 19, 2006)

[12] Bakari, J.K.; Tarimo, C.N.; Yngström, L. \& Magnusson, C. (2005) State of ICT Security in the Institutions of Higher Learning in Developing Countries: Tanzania Case Study, in Proceedings of the $3^{\text {rd }}$ International Workshop on Technology for Education in Developing Countries, 6 July 2005, Kaohsiung, Taiwan, IEEE, 1007-1011.

[13] Personal communication with Ms Rose Kiishweko at the Higher Education Accreditation Council, Dar es Salaam, Tanzania on 24 May 2005.

[14] World Bank Organization (2006) Tanzania Data Profile. URL:

http://devdata.worldbank.org/external/CPProfile.as p?CCODE=TZA\&PTYPE=CP (Jan 19, 2006)

[15] Population and Housing Census (2002) The United Republic of Tanzania. URL:

http://www.tanzania.go.tz/census/iringa.htm (Jan 19, 2006) 
[16] The President's Office - Planning And Privatization (2005) The Economic Survey 2004, Developments in Different Sectors of the Economy. The United Republic of Tanzania. URL: http://www.tanzania.go.tz/economicsurvey1/2004/ part4/education.htm (Jan 10, 2006)

[17] Kemppainen, J. (2005) Implementation of the Internet Project Strategic Plan of Tumaini University/lringa University College in 2001-2003. A Finnish ICT expatriate as an action researcher. B.Sc. Thesis, University of Joensuu, Finland.

[18] Ashford, R. (1999) Internet Project Strategic Plan. Tumaini University, Iringa University College.

[19] Ashford, R. (2000) "Four-Point Plan" for Internet Project. Tumaini University, Iringa University College.

[20] Ministry for Foreign Affairs, Department for Development Cooperation, Finland (2000) Development Cooperation Manual for NonGovernmental Organizations, Part 2.

[21] World Commission on Environment and Development WCED (1987) Our Common Future. Oxford: Oxford University Press.

[22] Tumaini University/Iringa University College (2001-2004), IPSP's Annual Report for Ministry for Foreign Affairs, Finland, 2001-2004.

[23] Tumaini University (1999-2004), Prospectuses 1999-2004.

[24] Personal communication with ICT Director Emmanuel Lupilya, Tumaini University, on 10 April 2005, Joensuu, Finland.

[25] Lund, H.H.; Nielsen, J.; Sutinen, E. \& Vesisenaho, M. (2005) In Search of the Point-ofContact: Contextualized Technology Refreshes ICT Teaching in Tanzania, in Proceedings of the $3^{\text {rd }}$ International Workshop on Technology for Education in Developing Countries, 6 July 2005, Kaohsiung, Taiwan, IEEE, 983-987.

[26] Duveskog, M.; Sutinen, E.; Tedre, M. \& Vesisenaho, M. (2003) In Search of Contextual Teaching of Programming in a Tanzanian Secondary School, in Proceedings of the $33^{\text {rd }}$ Frontiers in Education Conference (FIE), 5-8 November 2003, Boulder, Colorado, USA, IEEE.

[27] Laisser, E.; Lupilya, E. \& Vesisenaho, M. (2003) Information and Communication Technology (ICT) for Contextual Development, in Proceedings of the First Conference on Educational Technology in Cultural Context, 2-3 September 2002, Joensuu, Finland, University of Joensuu, Department of Computer Science, International Proceedings Series 3, 105-116.
(2002) e-Based and Contact-Based Computing Studies for Tanzania: Action Research from Challenges via Changes to Chances, in Proceedings of the $7^{\text {th }}$ International Working Conference of International Federation of Information Processing (IFIP), Information Technology in Developing Countries (WG 9.4), 29-31 May 2002, Bangalore, India, IFIP, 444-452.

[29] Vesisenaho, M.O. \& Lund, H. H. (2004) IBLOCKS for ICT Education Development, Case Iringa, Tanzania, in Proceedings of the 33. International Symposium IGIP / IEEE / ASEE, 2730 September 2004, Fribourg, Switzerland, University of Applied Sciences of Western Switzerland, $364-371$.

[30] Sutinen, E.; Duveskog, M.; Eronen, P. J.; Tedre, M. \& Vesisenaho, M. (2005) ICT Education for Local Development, in (ed. Olli Hietanen) University Partnerships for International Development: Finnish Development Knowledge. FFRC-Publications 6/2005. Turku, Turku School of Economics and Business Administration, 235253.

[31] The American Heritage Dictionary of the English Language (2000) $4^{\text {th }}$ Edition. Houghton Miffin Company.

[32] Eglash, R. \& Tedre, M. (forthcoming) Ethnocomputing: An Overview. To appear in Software Studies, MIT Press, 2007.

[33] Knuth, D. E. (1991) Theory and Practice. Theoretical Computer Science 90(1991): 1-15.

[34] Stevenson, D.E. (1993) Science, Computational Science and Computer Science: At a Crossroads. Communications of the ACM 37(12), December 1994: 85-96.

[35] Eglash, R.; Crossiant, J.; Di Chiro, G. \& Fouché, R. (2004) Appropriating Technology: Vernacular Science and Social Power. Minnesota: University of Minnesota Press.

[28] Sutinen, E.; Vesisenaho, M. \& Virnes, M. 


\section{Biography}

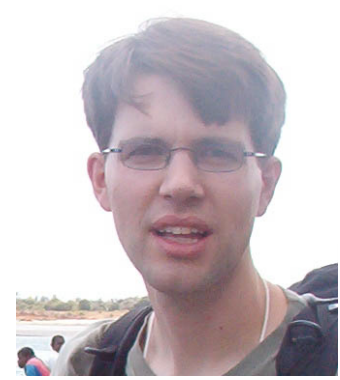

Mikko Vesisenaho, M.Ed., is a doctoral student in the Department of Computer Science at the University of Joensuu, Finland. His research interest is higher level ICT education in developing countries. Between 2003 and 2005 he worked as a researcher and as project manager for the project ICT Education for Development: $A$ Tanzanian Perspective. He has been involved for several years in ICT education in the fields of education and computer science.

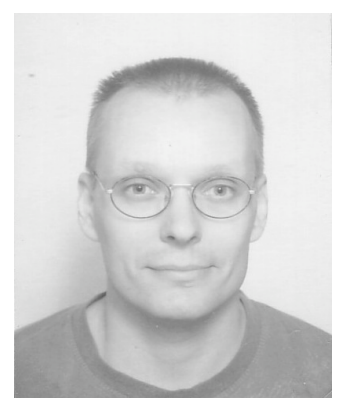

Jyri Kemppainen graduated as an automation engineer from Jyväskylä Institute of Technology in 1989. After his graduation he worked for a few years as a programmer, and then as a member of an ICT support and development team in a large Finnish company, Kemira. He subsequently worked for seven years in ICT education in Tanzania while teaching and working in Iringa University College of Tumaini University (Tanzania). In his first two years at Tumaini University, he taught computer literacy as an Assistant Lecturer in Computer Science. He was then placed in charge of all computer-related ICT support and development activities in the Faculty of Education and the Administration in the university. He is now studying computer science at the University of Joensuu.

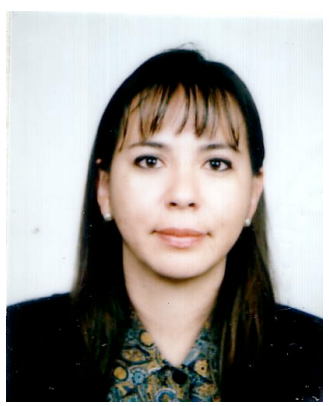

Carolina A. Islas Sedano, M.Sc., is a doctoral student in the IMPDET Program of the Department of Computer Science at the University of Joensuu, Finland. She obtained her B.Sc. in Electronic Engineering from Universidad Iberoamericana in Mexico City, and her M.Sc. in Communication and Media Engineering in Offenburg, Germany. Her research interests lie in the development and implementation of ICT applications in different cultural settings and environments.

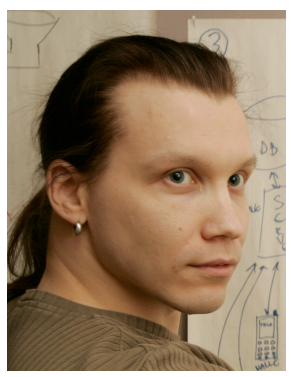

Matti Tedre, M.Sc., is a teaching assistant and a doctoral student in the Department of Computer Science at the University of Joensuu, Finland. He currently conducts research into ethnocomputing, social studies of computer science, and global netiquette.

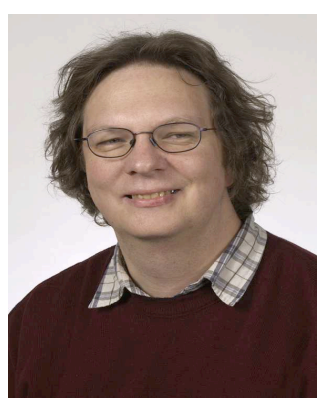

Erkki Sutinen, Ph.D., is a professor of Computer Science at the University of Joensuu, Finland. He is head of the edTech ${ }^{\Delta}$ research group (www.cs.joensuu.fi/edtech) and the IMPDET International $\mathrm{PhD}$ School in Educational Technology (www.impdet.org). His research interests include ICT education in developing countries, the development of learning tools such 
as visualization and digital portfolios, the influence of cultural factors in educational technology, computer science education, and information retrieval/string algorithms. $\mathrm{He}$ is a program committee member for several international conferences, and has in the past few years regularly launched initiatives that promote computer science educational technologies. He has conducted many tutorials and delivered numerous papers at international and national conferences. He is also the co-author of more than 100 research papers. He currently directs several research and development projects that are funded by (among other sponsors) the Academy of Finland, various European Union funds, and the National Technology Agency (Tekes). 